\title{
Interpretación del sueño en personas que asisten a una ceremonia de yage ${ }^{3}$
}

Ángela M. Ayala Santacruz

Psicóloga

Universidad Mariana de Pasto, Colombia Correo electrónico: angayala@umariana.edu.co

Luis C. Rosero García Magister en Etnoliteratura Universidad Mariana de Pasto, Colombia Correo electrónico: Irosero@umariana.edu.co

\section{Resumen}

El fenómeno onírico, denominado sueño, resulta de gran importancia e interés para todos los seres humanos a lo largo de la historia; por ende, se realizó una investigación del mismo en el marco de la ceremonia de consumo de yagé, donde se buscó realizar una interpretación del significado inconsciente que posee, empleando tres categorías de análisis que resultan de gran importancia en el sueño y permiten generar y fortalecer la construcción de la interpretación. En primer lugar, se retomaron los restos diurnos como una parte de gran trascendencia en el sueño, seguido de los símbolos como la representación de los contenidos inconscientes; por último, se indagó en cuanto a la censura para identificar los efectos que genera durante el sueño. Cabe señalar que para la recolección de la información se hizo uso de dos instrumentos, a saber, la entrevista semi estructurada y el grupo focal.

\section{Palabras clave}

Sueño, Interpretación, Inconsciente, Medicina tradicional.

3 Para citar este artículo: Ayala, A.M. \& Rosero, L.C. (2019). Interpretación del sueño en personas que asisten a una ceremonia de yage. Informes Psicológicos, 19(1), pp. 49-68 http://dx.doi.org/10.18566/infpsic.v19n1a03 


\title{
Interpretation of dreaming in people attending a yagé ceremony
}

\begin{abstract}
Dreaming is an oneiric phenomenon that has been of great importance and interest to all human beings throughout history. An investigation was carried out in the context of the yagé consumption ceremony, looking to interpret the unconscious meaning underlying in it. Three categories of analysis were used, which are of importance in the dream and allow to generate and strengthen the interpretation. In the first place, the day residues were taken as a part of great transcendence in the dream, followed by the symbols as the representation of the unconscious contents. Finally, we investigated the censorship to identify the effects generated during the dream. It should be noted that two instruments were used to collect the information: the semi-structured interview and the focus group.
\end{abstract}

Keywords

Dream, interpretation, unconscious, traditional medicine.

\section{Interpretação dos sonhos nas pessoas que participam de uma cerimônia de yagé}

Resumo

0 fenômeno onírico, chamado sono, é de grande importância e interesse para todos os seres humanos ao longo da história; portanto, realizou-se uma investigação do mesmo no contexto da cerimónia do consumo de yagé, onde se buscou uma interpretação do significado inconsciente que ele possui, utilizando três categorias de análise que são de grande importância no sonho e permitem gerar e fortalecer a construção da interpretação. Em primeiro lugar, os restos diurnos foram tomados como parte de grande transcendência no sonho, seguidos pelos símbolos como representação do conteúdo inconsciente; finalmente, investigamos a censura para identificar os efeitos gerados durante 0 sonho. Deve-se notar que dois instrumentos foram utilizados para coletar as informações, a saber, a entrevista semiestruturada e 0 grupo focal.

Palavras chave Sonho, interpretação, inconsciente, medicina tradicional. 


\section{ntroducción}

Para efectos de la construcción del presente artículo se toma como eje disciplinar al sueño como formación del inconsciente, el cual fue objeto de análisis investigativo a partir de la recolección de información con un grupo de personas que asisten a las ceremonias de toma de yagé. Como proceso metodológico de la investigación de la cual surge este texto, se aislaron unas categorías de análisis, que son: restos diurnos, símbolos y censura. A continuación, se hace la presentación de los resultados generales de la investigación en mención.

En primera instancia, cabe señalar que el sueño corresponde a un fenómeno de gran transcendencia en la historia y la cultura del ser humano, por ende, se considera de gran importancia indagar el significado del mismo durante una ceremonia de yagé, siendo ésta una medicina tradicional andina que se encuentra ligada a la cultura y espiritualidad de quienes la manejan. En cuanto al sueño, Freud (1900) refiere que es "la vía regia hacia el conocimiento de lo inconsciente dentro de la vida anímica" (p.597), debido a que durante el sueño los mecanismos de defensa disminuyen de forma significativa, facilitando el acceso a los contenidos del sistema inconsciente. Este fenómeno se ve influenciado por el yagé y el contexto donde se presenta. En relación a lo anterior, Nathan (2012) refiere que es importante considerar el entorno del sujeto, puesto que resulta significativo comprender que, durante la ceremonia de toma de yagé, el sueño manifiesta características particulares en los sujetos participantes, de acuerdo a su particular relación con la espiritualidad y procesos de curación.

En esta instancia es importante afirmar que se utilizará el psicoanálisis como herramienta para realizar una interpretación puesto que, según Gastelumendi (2012), el mismo resulta adecuado debido a que posee la complejidad necesaria a la hora de comprender la psique de los sujetos. Por otro lado, existen semejanzas en cuanto a las finalidades que posee el uso del yagé, como un proceso de autoconocimiento y de toma de consciencia y el proceso terapéutico encaminado desde el psicoanálisis.

Los sujetos que participaron en la investigación acuden a las ceremonias de yagé efectuadas en la maloca Kahansy Thesy, ubicada en el corregimiento de Mocondino, que, según el Ministerio de Cultura y Turismo de Pasto (2015), se encuentra ubicado a tres kilómetros de la ciudad de Pasto. Las ceremonias de yagé son oficiadas por el Taita Querubín Queta Alvarado, líder y primera autoridad del resguardo indígena Ukumari Kankhe del pueblo Cofán que, según Jimeno, Correa y Vásquez (1998), hace parte del resguardo de Santa Rosa de Sucumbíos.

Durante la ceremonia de yagé se presentan tanto alucinaciones, también llamadas "pintas", como el fenómeno onírico denominado sueño; por ende, es importante aclarar que la alucinación corresponde, según Ball (1890), a una percepción errónea y un error de los sentidos que, dentro de la cultura del yagé, posee importancia, 
sin embargo, en el presente artículo no se centrará en ella.

En cuanto al sueño, y según Freud (1992), se considera un medio de comunicación que posee el sistema inconsciente, donde quedan registrados los contenidos propios del mismo, aunque estos se ven afectados por los distintos mecanismos generados por la censura y la represión. Teniendo en cuenta lo mencionado con anterioridad, y para cumplir con el objetivo central que busca la comprensión del significado inconsciente del sueño en la ceremonia de yagé, se hace uso de los restos diurnos, los cuales son definidos por Laplanche y Pontalis (1994) como una parte de gran importancia durante el sueño que, junto con otros aspectos, componen el contenido latente del sueño y son modificados por instancias psíquicas del ser humano; estos proceden del estado de vigilia del sujeto.

Por otro lado, los símbolos, que se evidencian de forma recurrente en el sueño (y más aún en el que se presenta durante la ceremonia de yagé) hacen referencia, según Fromm (2012), a "algo que representa otra cosa" (p. 14), es decir, se trata de un objeto, persona, o la escena que vivió durante un sueño, que encarna algo que se siente. De igual manera, el símbolo es algo exterior al sujeto y se destaca el papel de la censura en el sueño, la cual, según Freud (1900), ocasiona el olvido parcial que los recuerdos, ya que busca evitar que los pensamientos pertenecientes al sistema onírico accedan a la conciencia; por ende, se entiende que la censura desfigura al sueño ya sea haciendo que el sujeto olvide lo que ha observado o sentido durante el sueño, o que lo desfigure al tratar de recordarlo, decírselo a otro sujeto, o en el transcurso de un análisis.

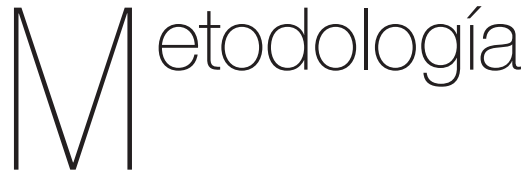

Paradigma

El presente texto es resultado de una investigación que se orientó según los preceptos del paradigma cualitativo (Hernández, Fernández \& Baptista, 2010), considerada como una metodología basada en la fenomenología, constructivismo, naturalismo e interpretativismo, donde el investigador puede elaborar un descubrimiento de la realidad para posteriormente interpretarlo. Igualmente, se establece que se trata de un paradigma abierto y flexible, por lo cual se considera adecuado para el estudio.

Se hace uso de este paradigma debido a que permite establecer una hipótesis en cuanto al sueño con el fin de argumentarla o desarrollarla basándose en teorías, las cuales pasan a ser su marco de referencia para, de esta manera, llegar a su comprobación; todo esto conlleva la recolección necesaria de información que, posterior a un análisis, culmina en la interpretación del fenómeno y la extracción del significado inconsciente del sueño.

\section{Enfoque}

Relacionado con lo anterior, la investigación acude al enfoque Histórico Hermenéutico, teniendo en cuenta que, según López (2001), éste elabora una comprensión de una de las distintas realidades existentes que implican aspectos históricos, psicológicos, ideológicos y lingüísticos. Mediante este enfoque se generó una comprensión e interpretación de un 
fenómeno onírico dentro del contexto de las medicinas tradicionales.

Tabla 1

Información demográfica.

\begin{tabular}{|c|c|c|c|}
\hline Sujetos & Cantidad & Edad & Escolaridad \\
\hline \multirow{2}{*}{ Hombres } & \multirow[b]{2}{*}{3} & \multirow[b]{2}{*}{22 a 29 años } & $\begin{array}{c}70 \% \text { : hasta } \\
\text { pregrado }\end{array}$ \\
\hline & & & $\begin{array}{l}\text { 30\%: con } \\
\text { Técnico. }\end{array}$ \\
\hline \multirow{3}{*}{ Mujeres } & \multirow{3}{*}{4} & \multirow{3}{*}{27 a 60 años } & $\begin{array}{c}50 \%: \\
\text { Bachiller }\end{array}$ \\
\hline & & & $\begin{array}{l}25 \% \text { : con } \\
\text { pregrado }\end{array}$ \\
\hline & & & $\begin{array}{c}25 \% \\
\text { Postgrado }\end{array}$ \\
\hline
\end{tabular}

Fuente: La investigación

\section{Tipo de investigación}

Teniendo en cuenta el interés de la investigación, se acudió al estudio de caso, puesto que se acomoda bastante a las necesidades adjuntas al carácter cualitativo, puesto que permitió indagar de manera más específica el sueño de los sujetos. Según Fontes, García \& Quintanilla (2015), los estudios de caso observan y comprenden la determinada situación de un sujeto, así como se interesan por el significado de algún aspecto de la realidad que posee el entrevistado, el cual se encuentra inmerso dentro de un contexto.

El estudio de caso es versátil ya que tiene la posibilidad de desarrollarse tanto con un sujeto o con más de uno. En la presente investigación fue constituido por un grupo de 8 sujetos donde se indagó el fenómeno onírico del sueño que se manifiesta en una ceremonia de ayahuasca; cabe resaltar que se tuvieron en cuenta los distintos aspectos en relación a la ceremonia y el contexto, que se enlaza con el marco teórico de la investigación, con el fin de elaborar una triangulación con la información obtenida y las distintas teorías utilizadas.

\section{Muestra}

En este apartado se hace una distinción entre la unidad de análisis y la unidad de trabajo (Hernández, Fernández \& Baptista, 2010). Con relación a la unidad de análisis, ésta corresponde a sujetos mayores de edad, de género tanto masculino como femenino, quienes con anterioridad han participado de las ceremonias de yagé una o más veces en la maloca Kahansy Thesy. La población en mención accedió a participar de forma voluntaria y firmaron un consentimiento informado con todas las indicaciones y la descripción de la presente investigación.

En cuanto a la unidad de trabajo, se encuentra conformada por ocho sujetos participantes en ceremonias de yagé y que, durante las mismas, experimentaron el proceso psíquico del sueño. Al hablar de los criterios de inclusión, es importante afirmar que los sujetos pertenecen a la ciudad de Pasto (Colombia), manifestaron la disposición voluntaria de participar en la entrevista y el grupo focal con el objetivo de indagar en cuanto al sueño y su significado inconsciente, así como la firma del consentimiento informado.

\section{Técnicas de recolección de información}

Con la finalidad de lograr una comprensión más detallada del sueño inmerso en la ceremonia de yagé se 
utilizaron dos técnicas de recolección, a saber, la Entrevista Semiestructurada, que permitió realizar un acercamiento a la población a partir de la extracción de información detallada en cuanto al sueño y los distintos aspectos que lo conforman.

Respecto a la entrevista, Bonilla y Rodríguez (1997) afirman que resulta un instrumento bastante útil, muy adecuado y ágil en el paradigma cualitativo, en cuanto a la indagación de un problema, para posteriormente elaborar una comprensión de éste, en la cual no existen categorías preconcebidas; por consiguiente, la información propiciada por los entrevistados no presenta ninguna intervención o cambio de acuerdo a las necesidades del entrevistador. Esto le permite al investigador conocer detalladamente las percepciones de los sujetos en relación a un suceso en concreto, las cuales resultan importantes para el proceso de investigación; de igual manera, por medio de este instrumento se establece una relación interpersonal entre los sujetos implicados, al igual que una comunicación cara a cara, lo que es un aspecto importante en la investigación.

Por otro lado, y con el objetivo de generar un espacio donde se indague y fortalezca el conocimiento en relación al sueño, se seleccionó el Grupo focal que, según Escobar y Fancy (2009), se define como un instrumento mediante el cual los sujetos de la investigación tienen la posibilidad de expresar sus sentimientos y creencias en el escenario de una conversación de tipo investigativa, guiada por un dinamizador y con unas preguntas orientadoras. Además, cabe afirmar que el grupo focal permite obtener múltiples puntos de vista y opiniones a partir de unas categorías de investigación.

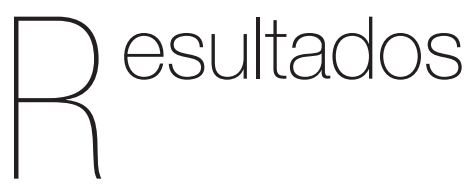

Tabla 2.

Matriz de categorización

\begin{tabular}{|c|c|c|}
\hline $\begin{array}{l}\text { Categoría } \\
\text { deductiva }\end{array}$ & $\begin{array}{l}\text { Técnica de reco- } \\
\text { lección y fuente }\end{array}$ & $\begin{array}{l}\text { Categorías } \\
\text { Inductivas }\end{array}$ \\
\hline Restos diurnos & $\begin{array}{l}\text { Entrevista Semi } \\
\text { estructurada } \\
\text { Grupo focal. } \\
\text { Sujetos (8) }\end{array}$ & $\begin{array}{c}\text { Acontecimiento } \\
\text { Representación } \\
\text { Muerte }\end{array}$ \\
\hline Símbolos & $\begin{array}{l}\text { Entrevista Semi } \\
\text { estructurada } \\
\text { Grupo focal. } \\
\text { Sujetos (8) }\end{array}$ & $\begin{array}{c}\text { Proyección } \\
\text { Desplazamiento } \\
\text { Figuras Zoomorfas } \\
\text { Metáforas } \\
\text { Inconsciente Étnico }\end{array}$ \\
\hline Censura & $\begin{array}{c}\text { Entrevista Semi } \\
\text { estructurada } \\
\text { Grupo focal. } \\
\text { Sujetos (8) }\end{array}$ & $\begin{array}{l}\text { Retorno de lo } \\
\text { Reprimido } \\
\text { Información }\end{array}$ \\
\hline
\end{tabular}

Fuente: La investigación

Durante la recolección de información referente al sueño en la toma de yagé, se evidenciaron categorías emergentes que resultan de vital importancia para la construcción de la interpretación del sueño.

Al hablar de los restos diurnos, la mayoría de los sujetos manifestaron que durante la toma lograron visualizar o experimentar acontecimientos de vital importancia en el transcurso de su vida consciente. Por otro lado, en los discursos de la población se resaltó la insistencia del papel de la representación, siendo ésta un aspecto recurrente. 
Dentro de la segunda categoría empleada para internarse en los terrenos del sueño inmersos en la toma de yagé, se evidenció, en primer lugar, la recurrencia de procesos, tanto proyectivos como introyectivos, así como los referentes al desplazamiento. De igual forma, se lograron identificar figuras zoomorfas, tanto de seres relacionados con el contexto y la cultura de la población, como aquellos que no poseen una estrecha relación con los sujetos.

Además, y dentro de la presente categoría en el sueño, se encontró la presencia de símbolos procedentes del inconsciente colectivo o étnico, lo que se encuentra íntimamente ligado con la aparición y visualización de fractales y figuras religiosas. Cabe resaltar que, en relación a lo mencionado con anterioridad, se encontró la metáfora, debido a las características que poseen los sueños de los sujetos y a la interpretación otorgada por los mismos.

Por último, se halla la categoría denominada censura, dentro de la cual se resalta que en los sujetos se generaron procesos de retorno de lo reprimido, e inmerso en el discurso de los participantes se destaca la importancia de la categoría de información o conocimiento.

\section{Restos diurnos: una aproximación a lo inconsciente.}

El origen de esta parte del sueño se remite al periodo de vigilia vivenciado por el sujeto en un estado consciente; en esta instancia, es importante destacar que posterior a la recolección de información que fue brindada por la población, se identificó la recurrencia de los acontecimientos que, según Montenegro (2010), poseen la capacidad de modular fuerzas en el sujeto, causando efectos en los cuerpos. Por otro lado, también afirma que los acontecimientos no se encuentran en relación con el espacio, el orden o el cuerpo, sino más bien, presentan un carácter aleatorio y dejan marcas en los sujetos a los cuales ha atravesado y éstas se harán evidentes posteriormente; de ahí que se puede conocer la historia y de donde provienen los sujetos, en función de los acontecimientos y las marcas que éstos generan.

Dentro de los discursos de los sujetos participantes, se destacan narraciones de acontecimientos tanto de su vida personal, de pareja y familiar las cuales resultan ser de gran importancia en la vida del sujeto. No es sólo una situación vivenciada con anterioridad que quedó anclada en la historia del sujeto, sino que, como lo define Montenegro (2010), se trata de un suceso que trasciende lo temporal, deja una marca en la existencia y delimita de cierta manera su actuar en la vida. En esta instancia, es importante destacar que la presencia del acontecimiento en el sueño de los sujetos permitió la experimentación de afectos ligados al mismo, lo que indica procesos de regresión que, según Gastelumendi (2012), se presentan debido a los efectos provocados por el yagé, los icaros (cantos de los taitas o chamanes que permiten la curación y posibilitan la visión en los sujetos), junto con el contexto donde se desarrolla la ceremonia, lo que contribuye en la realización de procesos de aceptación, como de aprendizaje y toma de consciencia en el sujeto, que para los mismos corresponde a la cura. 
Por consiguiente, se afirma que el revivir dichos acontecimientos en el discurso de los sujetos se convierten en indicadores de un proceso regresivo durante el fenómeno onírico inmerso en la ceremonia de yagé, y que se encuentra vinculado con la evocación de afectos displacenteros como tristeza, miedo, angustia, que, en un principio y al momento del acontecimiento, fueron provocados por el mismo. Por otro lado, es importante mencionar que las visualizaciones de acontecimientos llevan a una asociación libre para enlazarlos con la situación, generando un proceso de reflexión que indica una posible toma de consciencia e interpretación a fondo de lo observado, que resultan ser los contenidos provenientes del sistema inconsciente que los sujetos denominaron como acontecimientos importantes y susceptibles.

Rosero, Mora, Rosero, \& Martínez (2015) refieren, basados en la teoría de Foucault (1970), que el acontecimiento se define como una situación vivenciada por el sujeto que se encuentra cargada de afectos y que ocasionan señales en el mismo, las cuales se consideran vestigios de lo sucedido, ocasionando que el sujeto recuerde y evoque todos los sentimientos, emociones, afectos y demás características particulares del acontecimiento; de esta forma, durante la ceremonia de yagé, el sueño trae consigo el pasado a tiempo presente permitiendo una experimentación de un carácter más real.

Con relación a lo anterior, y dentro del discurso de los sujetos participantes, se identifica la representación como una categoría que denota elaboraciones psíquicas importantes en el sujeto.
En ese orden de ideas, ésta se considera, según Kaufmann (1996), el permitir la percepción en el ahora de un objeto, situación o signo que se encuentra ausente, y que se encuentra enlazada con la reproducción del pensamiento y la imagen, llevando la idea principal del acontecimiento, el cual figura como un referente.

En la población que fue parte del presente ejercicio investigativo se presentó de forma constante el hecho de revivir o representar los acontecimientos durante la ceremonia de yagé y estos trajeron consigo múltiples afectos, sentimientos y emociones al presente. Los acontecimientos vivenciados y representados durante la ceremonia de yagé fueron trascendentes en la vida del sujeto y causaron un impacto considerable en los mismos; los afectos ligados al mismo quedaron alojados en el sistema inconsciente cuando se originaron y, posteriormente, surgieron durante la ceremonia de yagé.

Estas representaciones le sirvieron como un estímulo para realizar procesos de toma de conciencia o de encuentro con lo real, ya que los acontecimientos eran olvidados por parte del sujeto, posiblemente debido a su contenido y a las posibles consecuencias que se tendría si se llegara a vivenciar de nuevo lo ocurrido. Como resultado de la experimentación en el sujeto de la representación durante el sueño, se genera un proceso de cambio psíquico que, según sus discursos, conlleva a mejoras en su vida.

Por otro lado, Chemama (1996) define la representación como un contenido de carácter concreto dentro de un pensamiento, y que elabora una diferenciación entre representación y afecto; cuando 
ocurre el acontecimiento y éste resulta ser de compleja asimilación para el sujeto, el afecto que lo acompañaba es transformado en energía somática, posibilitando la formación del síntoma. En cuanto a la representación, ésta resulta reprimida y posteriormente se tramita al sistema inconsciente, siendo inscrita en una huella mnémica.

Uno de los acontecimientos que se inscribió en el preconsciente o en el sistema inconsciente de los sujetos participantes fue la muerte y todo lo relacionado con la misma, lo que se evidencia dentro de los discursos referentes al sueño de la ceremonia de yagé de estos participantes. Ésta se presentó con significativa recurrencia y de gran trascendencia en el presente ejercicio investigativo. Según Freud (1915), la muerte ocasiona en el sujeto una posición de perturbación, resultando en una falsedad; por otro lado, se concluía que la muerte era y es el fin de lo que los sujetos denominan como la vida, haciendo referencia a un suceso indiscutible y totalmente inevitable. Sin embargo, la realidad de los sujetos es distinta, experimentan la vida tratando de prescindir de la muerte, convirtiéndose en un engaño totalmente creíble. Al hablar de los sujetos participantes, se evidencia que durante el sueño es revelado el verdadero significado de la muerte que, seguramente, se estaban negando experimentar. Los participantes observaron la representación tanto de su muerte como la de seres queridos, percibiendo así los afectos que se encuentran ligados a tan tortuoso acontecimiento.

De esta forma, pudieron experimentar la muertey todos los sentimientos, afectos, acontecimientos y demás aspectos enlazados con ella, ante lo cual manifestaron prestar mucha más atención, debido a que en su vida cotidiana no la experimentan a cabalidad. Así, y teniendo en cuenta lo mencionado por Freud (1915), hacen lo posible por huir y tenerla presente en sus vidas de forma mínima y aquel sujeto que la evoque es denominado insensible. El hecho de experimentar la muerte en un plano consciente, trae consigo algunos efectos de tipo inconsciente que permiten al sujeto reconciliarse con la muerte, por medio del enfrentamiento con lo real; de la misma manera, esto puede ocurrir mediante la literatura o la ficción y, posiblemente, dentro del sueño en la ceremonia de yagé, por medio de los mecanismos proyectivos e introyectivos.

En ciertos relatos, los sujetos declararon que reviven un acontecimiento con relación a la muerte que, a su consideración, le es ajena. Consecuentemente, y por medio del sueño en la ceremonia, el sujeto pudo vivenciar la muerte gracias de su representación y, de esta forma, reconciliarse con ella.

\section{El sueño como encrucijada y tejido de símbolos}

Tabla 3.

Clasificación de símbolos

\begin{tabular}{ccccc}
\hline Símbolos & $\begin{array}{c}\text { Figuras } \\
\text { zoomorfas }\end{array}$ & Muerte & Fractales & Religiosos \\
\hline Hombres & $50 \%$ & $100 \%$ & $100 \%$ & $50 \%$ \\
Mujeres & $100 \%$ & $100 \%$ & $90 \%$ & $100 \%$ \\
\hline
\end{tabular}

Fuente: la investigación.

Respecto a la segunda categoría deductiva denominada símbolo, se entiende que hace referencia a un elemento, ya sea físico, emocional o imaginario, el cual 
representa para el sujeto algo distinto a su esencia natural o común (Fromm, 2012). Un símbolo puede ser la representación de un afecto, un acontecimiento, un sujeto de importancia en la vida del soñante o algo que posea un significado dentro de su historia. Lo anterior pretende especificar la procedencia del símbolo ya que éste es exterior al sujeto, y lo que es simbolizado se encuentra dentro de él.

Inmerso en el discurso de los sujetos participantes en el ejercicio investigativo y dentro de la categoría de símbolo, se evidenció e identificó como categoría inductiva la proyección, la cual es definida por Brainsky (1981) como un conglomerado de procesos por parte del inconsciente que tienen como fin la externalización de características del Yo a otros. En el caso de los participantes de la investigación se evidencia la existencia de varios procesos de proyección durante el sueño, en los cuales adjudican características que poseen ellos a animales o distintos símbolos. Esto con el fin de generar procesos de sanación, debido a que el proyectarse con algún elemento ocasiona que el sujeto comience a realizar un proceso de interpretación; posteriormente, sobreviene una toma de conciencia que culmina con un encuentro con lo real, seguido de un proceso de aceptación y rectificación subjetiva.

En relación a lo anterior, es importante destacar que Brainsky (1981) afirma que no existen procesos de proyección sin introyección, ante lo que se establece que los sujetos soñantes equiparan características propias como aspectos de un símbolo; al mismo tiempo, las características del símbolo pasan a ser también características del sujeto.
En este orden de ideas, Freud (1954) denomina a la proyección junto con la introyección como los procesos que hacen parte de la estructura y funcionamiento del yo. Con relación a la proyección, este mecanismo de defensa atribuye a otro sujeto, ideas e impulsos que le resultan inaceptables.

De igual forma, se evidencian procesos de desplazamiento, definidos por Laplanche y Pontalis (1994) como un movimiento en la carga energética de una representación significativa a otra con menos importancia dentro de la psique del sujeto, lo que se evidencia en gran medida durante el discurso referente a la visualización de figuras que, en un principio, no tenían carga energética o un significado trascendente que, posterior a la observación, adquiere energía, además de los afectos procedentes de una representación de importancia para el sujeto, como el hecho de observar figuras zoomorfas procedentes de otras culturas o de lugares distintos.

Teniendo en cuenta lo mencionado anteriormente, es importante destacar que, durante el fenómeno onírico, diversos sujetos observaron múltiples figuras de animales, las cuales se toman como figuras zoomorfas que, dentro de esta investigación, pasarían a ser una de las categorías inductivas. El hecho de observar ese tipo de figuras causó impacto en los sujetos; por otro lado, la importancia atribuida específicamente a este tipo de símbolos se encuentra enlazada a los procesos, proyectivos, introyectivos y de desplazamiento, que los sujetos efectúan durante el sueño. 
Las figuras zoomorfas resultan como vehículos o medios de expresión para los afectos, características del sujeto o contenidos procedentes del inconsciente que se representan de esta forma debido a los diversos mecanismos que modifican los contenidos durante el fenómeno onírico. En esta instancia cabe destacar la importancia que poseen las figuras zoomorfas dentro de las culturas y grupos indígenas colombianos; sobre el tema, Rodríguez (2011) afirma que existen tanto asociaciones como relaciones entre las distintas figuras humanas y las animales, debido al papel que cumplían los animales en la cultura de la cual hacían parte.

Existe un interés especial hacia las serpientes, tanto en las comunidades latinoamericanas como en comunidades exteriores. Rodríguez (2011) afirma que la serpiente, en especial la anaconda, posee una importancia destacable ya que se encuentra íntimamente asociada con diversos mitos. En el caso de los arahuacos, la serpiente representa el paso del tiempo; según Dolmatoff (2005, citado por Rodríguez, 2011) la serpiente "es la expresión gráfica de un concepto uterino cuyo modelo fue la culebra progenitora" (p. 161). En el caso particular de la maloca Kahansi Thesy, cabe mencionar, en primer lugar, que el recinto lleva el nombre de una serpiente, la boa, y, según los sujetos, el espacio físico de la maloca posee la forma de la misma serpiente y posee dentro de la comunidad un significado de sanación; en segundo lugar, el abuelo (como también es llamado el chamán o taita) posee características de un tigre.

De esta forma, se entiende que todas las figuras zoomorfas poseen atributos o características otorgadas, ya sea de manera individual y durante el sueño en la ceremonia o su posterior interpretación por parte del sujeto; así mismo, se le atribuye un significado de forma colectiva dentro del grupo étnico o cultural al cual pertenecen. Por ende, en este momento se enlaza al proceso interpretativo el tema del inconsciente étnico como una categoría importante.

Teniendo en cuenta que la interpretación o la significación atribuida a un símbolo observado o percibido durante el sueño presente en la ceremonia, puede surgir desde lo que se encuentra en el sistema inconsciente del sujeto o del inconsciente étnico. En múltiples discursos de los participantes se evidencian claramente contenidos procedentes de lo que se conoce como inconsciente étnico o cultural, el cual es definido por Devereux (1973, citado por Francisco, 2008) como un inconsciente proveniente del sujeto que se encuentra conformado por contenidos que proceden del grupo cultural del cual hace parte. Estos contenidos son reprimidos en los sujetos que integran la cultura y resultan ser compartidos por los mismos, al igual que los distintos conflictos propios del sistema inconsciente que son generados mediante lo que es reprimido.

En cuanto a lo mencionado con anterioridad, se trata de contenidos que se transmiten de generación en generación. En el presente contexto en particular, es importante destacar el conjunto de figuras y formas observadas en el que son representativas de las ceremonias de yagé, las cuales poseen características íntimamente ligadas con la cultura, y que en ciertas ocasiones son denominadas pintas; este tipo de observaciones son recurrentes y poseen un significado en particular dentro de la cultura y la población 
que ceremonia yagé, indicando la presencia de un inconsciente étnico propio del contexto.

El inconsciente étnico se puede evidenciar en las múltiples representaciones de aspectos religiosos en los sueños de los participantes y, en segundo lugar, en las figuras zoomorfas que se mencionaron con anterioridad. En cuanto a las figuras con relación a las creencias, la figura de la virgen es referenciada en múltiples ocasiones, con gran trascendencia e impacto en los sujetos, lo que se compara con la representación de la figura femenina, destacando la importancia que posee en la cultura y en la propia subjetividad, siendo la misma una representación de múltiples consideraciones.

En segunda instancia, se destaca la concepción de Rodríguez (2011) en cuanto al inconsciente étnico o también denominado inconsciente cultural, el cual involucra los distintos mitos e ideologías, la forma de comportamiento y de vida de los miembros de una cultura, su lenguaje o su forma de gobierno, entre otras. En el caso de la presente investigación, se enlazaría con la observación de animales que resultan ser propios de la región, que son importantes en la cultura y poseen una denotación significativa para los sujetos; de igual forma, se identifica una posición en cuanto al pensamiento de los sujetos, donde se denomina a los animales como sagrados, adjudicándoles características humanas y evidenciando nuevos procesos de proyección.

Retomando otro tipo de simbología presente en los sujetos soñantes, se destacan los fractales como una categoría inductiva, los cuales son definidos por Velasco (2003) como un objeto geométrico y complejo, de forma irregular, en donde se evidencia una replicación de la estructura básica donde se producen estructuras auto semejantes. Una característica fundamental del fractal es que se encuentra íntimamente relacionado con fenómenos caóticos indicando el caos en múltiples situaciones.

Con relación a lo anterior, se deduce que la representación de los fractales en el sueño indica la influencia del contexto y de la bebida yagé, además como un medio de representación de los contenidos del sistema inconsciente del sujeto que se evidencian en el discurso del mismo, donde plasma, por medio del fractal, sus afectos, experiencias y distintas situaciones de su vida.

Desde esta perspectiva, los sujetos yuxtaponen las características caóticas del fractal con situaciones de su vida lo que indica procesos de asociación libre e interpretación que llevan al sujeto a enfrentarse con lo real. La aparición de fractales es recurrente, tanto en el sueño como en el trance de la ceremonia de yagé. En este sentido, Mejía \& Rico (2003) afirman que en la experimentación de sustancias enteógenas se evidencian figuras geométricas que se encuentran en movimiento y pueden presentar apariencia de mandalas o imágenes caleidoscópicas. Estas imágenes, al ser organizadas, pueden formar y conformar una visión de animales, personas o plantas, que poseen significado particular ya sea para el sujeto o para la comunidad. En esta instancia se destaca el aspecto metafórico de lo observado en la ceremonia de yagé y se identifica a la metáfora como una categoría inductiva de la presente investigación.

En este orden de ideas, y retomando a Lacan (1955), define la metáfora como el 
cambio o remplazo de algo por un significante, proceso en el cual, el significado que se encuentra oculto no se ausenta o substituye debido a la conexión metonímica que posee en la cadena de significantes, y, por tanto, permanece a pesar del movimiento que se ha efectuado.

En esta instancia, y a partir del discurso de los sujetos, se logró identificar una interpretación propia por parte de estos donde elaboran asociaciones entre lo observado y vivenciado en el sueño de la ceremonia y los distintos acontecimientos experimentados con anterioridad, dando cuenta de procesos de toma de conciencia e introspección, los cuales son considerados como aprendizajes. Por otro lado, es importante destacar que el contenido de las metáforas, observadas o evidenciadas en el sueño, o el significado real de las mismas al ser parte del sueño, procede del sistema inconsciente, por consiguiente, a los sujetos les resulta difícil la interpretación debido a sus características.

De lo anterior, se deduce que el contenido del sueño es metafórico debido a que corresponde y tiene como origen el sistema inconsciente, por ende, la interpretación de los mismos se efectúa por medio de la asociación libre, donde los afectos provenientes del sistema inconsciente son enlazados con algo y esto permite que el sujeto encuentre el significado real y proceda a aceptarlo.

\section{Censura: un velo atravesado por la liana de los muertos}

Se entiende que la censura se constituye como una herramienta del sujeto para mantener alejado de su sistema consciente contenidos que le son ajenos $y$, en consecuencia, provenientes del sistema inconsciente. Estos contenidos, al surgir, posiblemente causarían en el sujeto múltiples sensaciones de displacer debido a las características que los mismos presentan; por esta razón, la censura funciona como una cortina que esconde detrás de sí todo aquello que no es aceptado, oculta un mundo de realidad y de verdad que, aunque existe, muy pocas veces se puede acceder a él, y solo permite hacer visible a la conciencia un fragmento de tales contenidos.

Sin embargo, la liana de las almas, o como es llamado por poblaciones indígenas conocedoras al sagrado bejuco de yagé, logra atravesar ese velo que es la censura, así como ayuda al sujeto a traspasar del plano físico al mundo de las almas o de los muertos. Según la cosmovisión andina, el plano de los muertos tendría un aspecto similar con el sistema inconsciente, debido a sus características: se trata de un lugar donde se encuentran aquellas cosas que no son tan fáciles de ver, aquello escondido a la vista del sujeto y a la luz del día. Los dos lugares guardan aquello que no es muy fácil de comprender y que no se revela fácilmente; por tal motivo, durante el sueño, tanto en la vida cotidiana como en el que se presenta en la ceremonia de yagé, el sujeto se encuentra con el sistema inconsciente y sus contenidos o con el mundo de las almas.

Durante el sueño de los sujetos, el yagé les permitió adentrarse en aquellos terrenos, enfrentándose cara a cara y sin ninguna defensa a aquello que estaba escondido, aunque no de forma consciente. Proceso que, según 
el psicoanálisis, se puede denominar como un retorno de lo reprimido, como un mecanismo donde los contenidos reprimidos reaparecen, así sea deformados (Laplanche y Pontalis, 1994). Esto se debe a que los elementos pertenecientes al inconsciente no son eliminados en su totalidad, es decir, estos se encuentran alojados de forma silenciosa en los terrenos del inconsciente, y reaparecen en la conciencia en formas que no son fáciles de interpretar.

En múltiples discursos se evidencia de forma clara el retorno de lo reprimido, puesto que los sujetos durante la ceremonia de yagé observan y experimentan aquello que serían los contenidos propios del sistema inconsciente; sin embargo, luego de un tiempo, estos son parcialmente olvidados o distorsionados por la censura con el fin de no causar displacer; no obstante, los contenidos surgen de nuevo cuando son asociados con algún acontecimiento o situación similar y les permiten aparecer de nuevo en el sistema consciente.

El hecho de elaborar una asociación entre situaciones cotidianas que evocan contenidos del sueño, los cuales fueron reprimidos debido a su contenido, indica la existencia de múltiples cadenas de significantes y posibles maniobras generadas por la condensación y el desplazamiento que, según Brainsky (1981), son efectuadas por el Yo y se ejecutan con el fin de generar procesos de adaptación y defensa en el sujeto.

El proceso que fue mencionado con anterioridad, para los sujetos representa una adquisición de aprendizajes, con los conocimientos respectivos, los cuales claramente provienen del sistema inconsciente en cada sujeto que, gracias al retorno de lo reprimido y a la asociación, o como ellos lo toman (la posterior interpretación de lo observado en el sueño), se logra un proceso de catarsis, con la sanación correspondiente, producida por el encuentro del sujeto con los contenidos del sistema inconsciente.

Por consiguiente, la interpretación de lo representado en el sueño pasa a ser información y conocimiento para el sujeto. Este conocimiento, procedente de los contenidos del sistema inconsciente, debido a su importancia, fue conveniente retomarlo en el ejercicio investigativo como una de las categorías inductivas. Para Osorno (2015), el conocimiento hace referencia a una categoría difícil de definir, puesto que posee cierta fragilidad en el área de la academia debido a la influencia de la lógica generada por occidente, respecto a la validación científica o no científica del mismo.

Por otro lado, este mismo autor destaca el conocimiento no científico como válido, ya que el conocimiento puede remitirse a lo espiritual, a lo ancestral, a la sabiduría que brindan los mayores o los abuelos, a una realidad de la comunidad, que no necesita ser validada por el método científico; este conocimiento posibilita saber de dónde proviene el sujeto, sus raíces y la identidad, permitiendo al sujeto vivir en armonía con todo tipo de seres y consigo mismo. Al presentarse este tipo de conocimiento inmerso en el sueño de la ceremonia, en ocasiones puede que se vea afectado por la censura debido a sus particularidades. Esta información procede tanto del inconsciente del sujeto como de los saberes que otorga el yagé, que, a su vez, resulta de gran impacto en el sujeto, debido a la carga afectiva que 
traen consigo y por lo que son nuevamente reprimidos, no sin antes dejar en el sujeto un vestigio de los mismos; en este sentido, les deja realizar procesos de asociación con situaciones o aspectos cotidianos.

En este orden de ideas, Osorno (2015) afirma que el conocimiento es concebido desde la ancestralidad y se origina junto con la experiencia, haciendo que la experimentación de ésta resulte intransferible, señalando que la interpretación del sueño en la ceremonia es distinta para cada sujeto soñante.

De lo anterior se puede deducir que el concepto de conocimiento va más lejos de lo que se conoce en la academia (esto es, asociado directamente a las implicaciones del método científico y relacionado íntimamente con la realidad), sino que llega al terreno de lo vivenciado por el sujeto, así como sus experiencias durante la ceremonia de yagé, lo que se encuentra enlazado con los contenidos propios del sistema inconsciente, los cuales son definidos por Chemama (1996) como aquellas representaciones que son reprimidas por el sujeto, correspondiendo a elementos que no poseen acceso a las instancias del preconsciente, puesto que se encuentran bajo el proceso primario, debido a que son contenidos pulsionales. En esta instancia, es importante destacar el papel que juega la ceremonia de yagé en el proceso de sanación del sujeto, ya que se considera como una herramienta usada con el fin de enfrentarse a aquello que no se ve o no se percibe fácilmente, para posteriormente lograr un proceso que involucre la aceptación y la toma de consciencia.
La investigación permite comprender que, en el momento en que el sujeto genera un cruce de los saberes de la comunidad, de lo experimentado en la ceremonia de yagé y los contenidos del sistema inconsciente, se ocasiona en el mismo un proceso de curación o sanación. Levi Strauss (1949, citado por Peña, 2000) afirma que la cura es volver pensable y asimilable en el sujeto un acontecimiento que el cuerpo no accede a tolerar. Es importante destacar que para Levi Strauss (1949, citado por Peña, 2000) la enfermedad posee doble perfil: uno biológico y otro social; bajo esta consideración, el chamán hace que el sujeto se regenere, ya sea por medio de mitos o ritos que sitúan al sujeto en la comunidad y en la sociedad. Así, en la presente investigación el ritual del yagé figura como el mecanismo que genera la cura en el sujeto.

Valga decir que, en este contexto, la cura se efectúa gracias a los procesos que ocurren en el sueño, con la consiguiente interpretación, la cual se encuentra cargada de procesos de asociación libre junto con autoanálisis. Por otro lado, el encuentro del sujeto con aquello que fue soñado hace que los conflictos o posibles eventos traumáticos, luego de ser observados y vivenciados de nuevo en el sueño, no generen displacer.

Con el material hermenéutico que la investigación ha ofrecido es posible hacer una breve disertación final con respecto a los significados que emergieron en un grupo de personas que asisten a una ceremonia de yagé. El significado pasa de ser un referente estrictamente cognitivo para mostrarnos sus aristas desde lo psíquico, lo social, lo étnico e incluso lo comunitario, todo ello pensado en función 
de la subjetividad del grupo participante en la investigación.

Los restos diurnos sirvieron como una brújula que permitió orientarse hacia la complejidad del acontecimiento, o más bien de su representación psíquica, y con ello de las construcciones que hacen el grupo participante acerca de un fenómeno muy interesante para la psicología como es la cura, entendida ésta, en el contexto de la investigación, como el encuentro con lo real del sujeto y de la cultura. En este mismo sentido, los restos diurnos dieron paso a reconocer la multiplicidad de voces e imágenes que hay en los símbolos: animales, figuras religiosas y fractales, que fueron apareciendo gracias al efecto que sobre lo inconsciente tienen mecanismos como la proyección y la introyección.

Finalmente, la investigación hizo un reconocimiento a la fuerza que tiene el mecanismo psíquico de la censura. Freud ya la había reconocido desde su texto "La interpretación de los sueños" (publicado originalmente en 1900), y aun antes en su trabajo clínico con la histeria, en este caso siguiendo el proceso de la represión. Quedó evidente que los contenidos que atravesaron los terrenos de la consciencia y llegaron hasta lo inconsciente se sometieron a los mecanismos que determinaron su deformación, gracias a los efectos de la censura; luego reaparecieron en los relatos de los sujetos participantes con una carga energética distinta y, a la vez, evidenciaron el proceso de retorno de lo reprimido.

El tema del sueño, y con ello de lo inconsciente, es un asunto que le interesa a la línea de investigación denominada Contextos y cultura, que hace parte de los referentes teóricos del grupo de investigación Desarrollo humano y social de la Universidad Mariana, de la ciudad de Pasto. Cabe mencionar que el presente texto es el resultado de una investigación estudiantil titulada "Interpretación del sueño en una toma de yagé", realizada bajo las directrices del Programa de Psicología de la mencionada universidad.

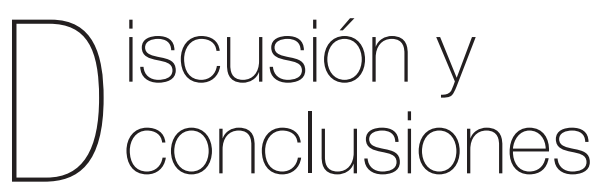

Teniendo en cuenta lo mencionado anteriormente, se puede destacar que el fin último y el resultado de la asistencia de los sujetos a las ceremonias de yagé, corresponde a procesos de curación y sanación los cuales involucran actos de pasaje y cambios psíquicos en el sujeto. Lo anterior es el fruto del encuentro del sujeto con lo real, que es generado por medio de la interpretación que los participantes le otorgan a lo observado durante el fenómeno onírico; se destaca la presencia de los acontecimientos que involucran vivencias traumáticas en el sueño, los cuales se evidenciaron por medio del estudio de los restos diurnos.

Durante el sueño en las ceremonias de yagé, por medio de representaciones exactas o metafóricas, los participantes pudieron observar aquellos acontecimientos que fueron de vital importancia en su vida, reconociendo la importancia en sí mismos y la manera como participaron como sujetos protagónicos en ellos. Como característica particular que acompañaba la aparición de los acontecimientos en el sueño se destacan los afectos a ellos vinculados, los cuales, en 
un comienzo, toman el lugar de huellas mnémicas que posteriormente quedarán alojadas en los terrenos del inconsciente, siendo, de esta manera, como surgen durante el sueño en la ceremonia.

Por otro lado, se destaca que existieron representaciones simbólicas de los acontecimientos, entre las que se encuentran las figuras zoomorfas como animales propios de la región o ligados a sus creencias espirituales o religiosas, los cuales le sirvieron como herramientas para realizar tanto proyecciones como introyecciones; de igual forma, los fractales cumplieron la misma función, puesto que permitieron que el sujeto identificara y reconociera características, tanto de su personalidad como de su vida que, durante su estado consciente, no podían ser distinguidos, puesto que al hacerlo podría generar displacer en el sujeto.

De igual forma, se evidencian múltiples representaciones de la muerte que, al manifestarse, generaron un encuentro con lo real y una reconciliación con la misma. En este orden de ideas, resulta de vital importancia resaltar el papel que posee la censura en el sueño durante la ceremonia, puesto que, gracias a ésta, lo observado en el sueño resulta distorsionado, provocando que el sujeto genere procesos de asociación libre, posteriores al retorno de lo reprimido; a aquellos contenidos a los cuales la censura ha afectado son denominados como información o conocimiento y su respectiva interpretación es considerada como un aprendizaje que contribuye con el proceso que se ha mencionado con anterioridad, esto es, la curación o sanación del sujeto.

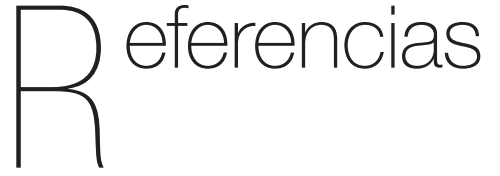

Ball, B. (1890). Lecciones clínicas sobre las enfermedades mentales. Paris: Editorial Asselin Et Houzeau.

Bonilla, E. \& Rodríguez, P. (1997). Más allá del dilema de los métodos. Buenos Aires: Norma.

Brainsky, S. (1981). Manual de psicología y psicopatología dinámicas. Fundamentos de psicoanálisis. Bogotá, Colombia: Carlos Valencia Editores.

Chemama, R. (1996). Diccionario del psicoanálisis. Diccionario actual de los significantes conceptos y matemas del psicoanálisis. Buenos Aires: Amorrortu.

Devereux, G. (1973). Ensayos de etnopsiquiatría general. Madrid: Barral.

Escobar, J. \& Fancy, I. (2009). Grupos Focales: una guía conceptual y metodológica. Cuadernos Hispanoamericanos de Psicología, 19(1), 51-67. Recuperado de http://www.uelbosque.edu.co/sites/ default/files/publicaciones/revistas/ cuadernos_hispanoamericanos_ psicologia/volumen9_numero1/articulo_5. pdf

Francisco, F. (2008). El Chamán como enfermo mental según George Devereux. Mérida: Anuario GRHIAL,1(2), 35-50.

Foucault, M. (1970). El orden del discurso. Barcelona. Tusquets.

Fontes, S., García, C. \& Quintanilla, L. (2015). Fundamentos de investigación en 
psicología. España: UNED-Universidad Nacional de Educación a Distancia.

Freud, A. (1954). El yo y los mecanismos de defensa. Buenos Aires: Paidós.

Freud, S. (1900). La interpretación de los sueños. Obras completas. Tomo IV. Madrid: Amorrortu.

Freud, S. (1914). Contribución a la historia del movimiento psicoanalítico Trabajos sobre metapsicología y otras obras. Obras Completas. Tomo XIV. Buenos Aires: Amorrortu.

Freud, S. (1915). Consideraciones de actualidad sobre la guerra y la muerte. Obras completas. Tomo II. Madrid: Biblioteca Nueva.

Fromm, E. (2012). El lenguaje olvidado: Introducción a la comprensión de los sueños, mitos y cuentos de hadas. España: Editorial Paidós Ibérica. Recuperado de https://books.google.com.co/books?id=N GnsVqvbCWgC\&printsec=frontcover\&hl=e s\&source=gbs_ge_summary_r\&cad=0\#v= onepage\&q\&f=false

Gastelumendi, E. (2013). Una mirada psicoanalítica a la experiencia con ayahuasca. Revista Psicoanálisis, 12(1), 91-110.

Hernández, R. Fernández, C. \& Baptista, P. (2010). Metodología de la investigación. Sexta edición. México: McGraw-Hill.

Jimeno, G., Correa, H.D., \& Luna, M. V. (1998). Hacia el reconocimiento de los derechos de los pueblos indígenas: conceptos de la Dirección General de Asuntos Indígenas 1995-1998. Bogotá: Dirección General de Asuntos Indígenas del Ministerio del Interior.
Kaufmann, P. (1996). Elementos para una enciclopedia de psicoanálisis. Buenos Aires: Paidós.

Lacan, J. (1955). Seminario 3. La psicosis. Barcelona: Paidós Ibérica.

Laplanche, J. \& Pontalis, J. (2004). Diccionario de psicoanálisis. Buenos Aires: Paidós.

Lévi-Strauss, C. (1949). La eficacia simbólica en Antropología estructural. Buenos Aires: Eudeba.

López, H. (2001). Investigación cualitativa y participativa. Un enfoque históricohermenéutico y crítico social en psicología y educación ambiental. Universidad Pontifica Bolivariana, 1(1) 80-129. Recuperado de http://sa4866e63be068bfc.jimcontent. com/download/version/1315184782/ module/5161506319/name/Enfoque\%20 Critico\%20Social.pdf

Ministerio de Cultura y Turismo de Pasto (2015). Mocondino. Ruta de la prehispanidad. Recuperado de http://www.culturapasto. gov.co/index.php?option=com_content\&vi ew=article\&id=122: mocondino\&catid=27:c orregimientos\&ltemid $=23$

Mejía, T. \& Rico, D. (2003). Resignificación de la identidad mediante el consumo de Yagé. Manizales: Centro de estudios avanzados en niñez y juventud alianza de la universidad de Manizales y el Cinde.

Montenegro, G. (2010). Foucault, poder y acontecimiento. Red de investigadores de Biopolítica, 12(1). 1-14. Recuperado de http://www.biopolitica.unsw.edu.au/ sites/all/files/publication_related_files/ montenegro_foucault_poder.pdf 
Nathan, T. (2012). La nueva interpretación de los sueños. Buenos Aires: Capital Intelectual.

Osorno, P. (2015). Saberes ancestrales y prácticas de formación cofanes "El conocimiento como recuerdo del olvido" (Tesis de Maestría). Universidad de Antioquia, Medellín (Colombia).

Peña, F. (2000). Más allá de la eficacia simbólica del chamanismo al psicoanálisis. Cuicuilco, 7(18), 1-17.

Rodríguez, J. (2011). Cosmovisión, chamanismo y ritualidad en el mundo prehispánico de Colombia. Esplendor, ocaso y renacimiento. Maguaré, 25(2), 145-195. Recuperado de https://revistas. unal.edu.co/index.php/maguare/article/ view/29892/39535

Rosero, L., Mora, L. Rosero, V. \& Martínez, A. (2016). Pulsión de muerte y conducta antisocial. Revista criterios, 23(1), 351-367.

Velasco, F. (2007). Caos, complejidad y proceso psicoanalítico. En C. Hanly (Presidencia) Simposio llevado a cabo en el $47^{\circ}$ Congreso Nacional de Psicoanálisis, Chiapas, México. 
Informes Psicológicos

68 Vol. 19 No. 1 • Enero-Junio $\bullet 2019$

ISSN - e: 2422-3271 